\title{
A study on the future of urban models in the third millennium: a sustainable urban model for Kurıkkale, Turkey
}

\author{
K. Özcan \& F. Eren \\ City and Regional Planning Department, University of Selcuk, \\ Konya, Turkey
}

\begin{abstract}
The aim of this paper is to determine an urban model for Kirıkale city according to the sustainable urban development potentials and dynamics. This model is dependent on the many planning decisions which include the assessment of ecological potentials, the foundation of urban open-green system and also the reorganization of the neigbourhoods in the city as the clusters.

In this paper, the methodology is based on the cluster analysis which consists of the assessment of the neighbourhoods in the city as named clusters and also transferring data onto maps according to the sustainable urban development dynamics and future potential.

This paper focused on Kirıkale city which is at an early stage for sustainable urban models in Turkey, but this paper also contributes towards the debate and study of sustainable urban models in Turkish towns according to the methodology.
\end{abstract}

Keywords: sustainability, urban development, urban model, Klrlkkale.

\section{Introduction}

The globalization process has brought shifts in power from national or local governments to international corporations. So national or local governments have been pressed to reduce their roles in controlling the flows of goods, capital and information flowing across their boundaries because of the progress in the communication and transportation technologies and systems. As a result of this 
progress, when the barriers on trade and investments have been removed, the issues on urban models in many countries have been started to study and debate by planners (Breheny [3], Frey [4], Haughton and Hunter [6], Haughton [5], Naes [7], Talvitie [8], Audirac-Fitzgerald [2]).

Over the past thirty years, the debates and studies on urban models are focused on the "sustainability" concept which is taking its base from "to supply the present generation needs without making concessions from the future generation needs" idea [1].

The aim of this paper is to determine an urban model for Kirıkkale city according to the sustainable urban development potentials and dynamics. This model is depending on the mainly planning decisions which include the assessment of ecological potentials, foundation of urban open-green system and also reorganization of the neighbourhoods in the city as the clusters.

In this paper, the methodology is based on the cluster analysis which consists of assessment of the neighbourhoods in the city as named clusters and also transferring data on to the maps according to the sustainable urban development dynamics and potentials to the future. Also, this paper focused on Kirikkale city is at an early stage for sustainable urban models in Turkey. But it is considered that this paper contributes towards the debates and studies on sustainable urban models in Turkish towns according to the methodology.

\section{The city of Kırıkkale}

Kırıkkale city as one of the cities in Central Anatolia like Ankara, Kırşehir and Kayseri is located in the Kizilirmak Valley in Turkey. In the provincial urban system in Turkey, each province is organized a central city and also the several towns which are depended on the central city according to the social, cultural, economical and administrative. In this context, Kirikkale city which has a population of about 200.000 people is the central city of Kirıkkale Province. The foundation of the city was based on the military and strategic industry investment called The Mechanical and Chemical Industries Corporation (MCIC) which was founded in 1929. As a result of this investment, Kirikkale city was faced with a rapid industrialization and urbanization process which has caused not only unplanned development but also environmental problems. At present, the city government, along with the central government, has maintained the development process by the national investments such as Middle Anatolian Petroleum Refinery, Organized Industry Zones, Free Zone, Kırıkkale University, Green Valley Tourism and Recreation Areas.

\section{Urban land use system in Kırıkkale city}

In this paper, the urban land use system in Kirkkale city is examined according to the sustainable urban models. In this context, it is indicated that the city indicates an urban model defined as linear development. The urban land uses were organized and distributed to the twenty-five neighbourhoods in the city (Figure 1). 
It is stated that they have been organized as the sections and also specialized in difference functions according to the dynamics and potential of urban development like central business district (CBD), existing housing areas, and development housing areas. In this frame, urban land uses in each of sections is analyzed and classified according to the urban densities (Figure 2).

Firstly, the section as named CBD is consisted of Hüseyin Kahya, Ovacık, Yenidoğan and Fabrikalar neighbourhoods, located in the center of the city. CBD is focused on urban facilities which serve for whole of the city according to the social, cultural, economical and administrative services. Unlike CBD, the neighbourhood is recognised as Sanayi, located in the northeast of the CBD. Not only it includes small industries depending on the automotive sector but also it is housing area with medium-densities.

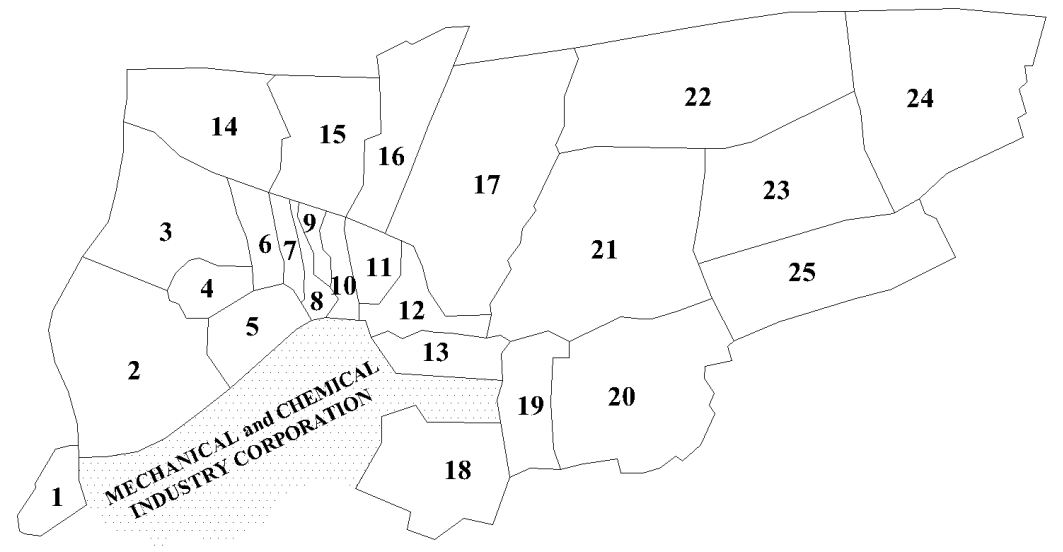

1-Kızılırmak 2-Yenimahalle 3-Çalılıöz 4-Yaylacık 5-Fabrikalar 6-Güzeltepe

7-Ovacık 8-Yenidoğan 9-Hüseyin Kahya 10-Tepebaşı 11-Gürler 12-Kurtuluş

13-Bahçelievler 14-Bağlarbaşı 15-Kaletepe 16-Etiler 17-Sanayi 18-Karşıyaka

19-Selim Özer 20-Yuva 21-Gündoğdu 22-Osman Gazi 23-Akşemseddin 24-Kimeski 25-Fatih

Figure 1: Key map, the neigbourhoods in Kırıkale city.

Secondly, the section as called existing housing area, located in surroundings of CBD. This section includes Gürler, Tepebaşı, Kurtuluş, Yaylacık and Güzeltepe neighbourhoods that the main function of them is housing areas with high-densities.

Thirdly, the section consists of Yenimahalle, Selim Özer, Çalılı̈z, Bağlarbaşı, Etiler, Sanayi, Karşıyaka and Bahçelievler neighbourhoods which are called as housing areas with medium-densities.

Finally, the section as named development housing areas with medium and also low-densities, located in the sphere of the city. This section includes the 
Osmangazi, Kaletepe, Kimeski Akşemsettin, Gündoğdu, Fatih and Yuva neighbourhoods which have difference densities. Both Osmangazi in the northeast of the city and Kaletepe in the northwest of the city are planned as mass housing areas. They are development housing areas with medium-densities. Unlike Osmangazi and Kaletepe, Kimeski neighbourhood is planned mass housing area with low-density like garden city. Akşemsettin, Fatih and Gündoğdu neighbourhoods in the east of the city and also Yuva in the southeast of the city are development housing areas with low-densities.

Also it is observed that these neighbourhoods especially Fatih and Yuva, are agricultural production areas. Besides, Kizılirmak neighbourhood in the southwest of the city is planned the prestige development housing area with low-densities.

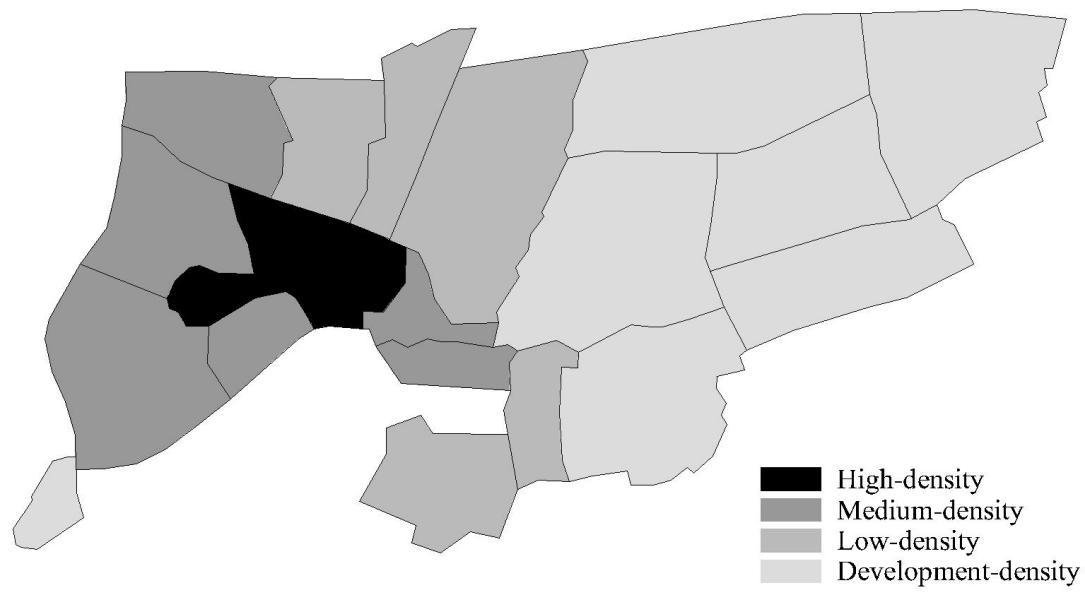

Figure 2: Distribution of population densities.

\section{Cluster analysis}

Cluster analysis is based on evaluating of the neighbourhoods in the city as the re-organized or revitalized sections according to the dynamics and potentials of sustainable urban development process near future. As a result of this evaluation, Kirkkale city is divided into ten clusters which are reorganized as sub-units for the criteria of sustainable urban development, in terms of their functional identities and spatial characteristics (Figure 3). In the frame, the functional and spatial characteristics in the each of cluster and also spatial sizes and densities of them are explained below (Table 1). 


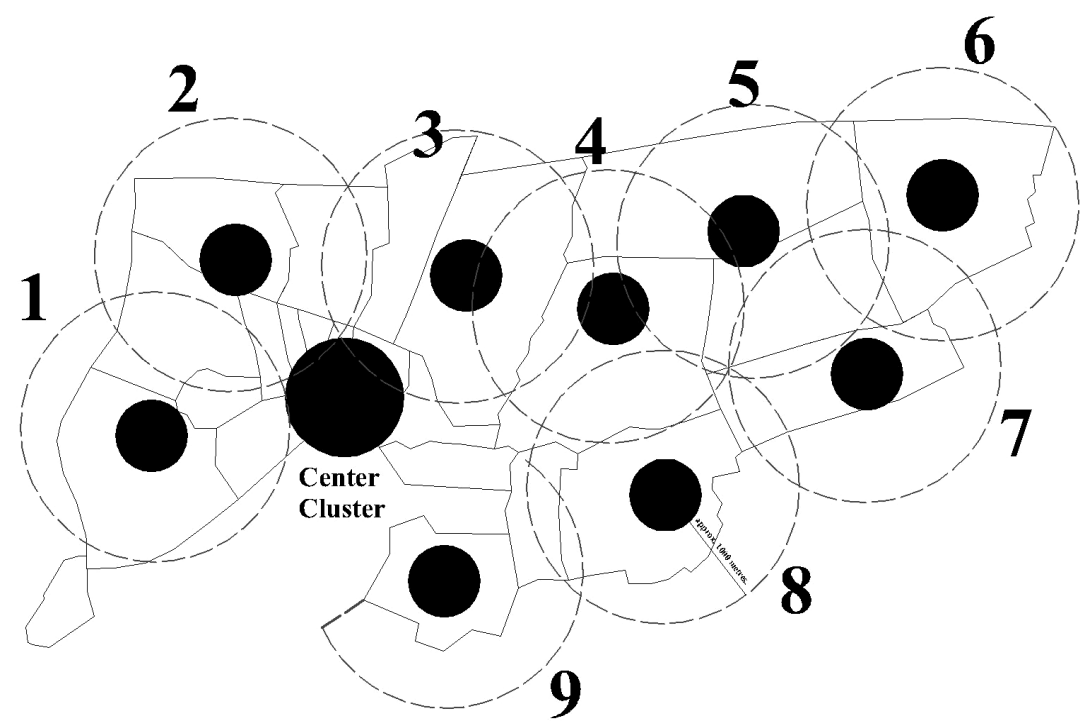

Figure 3: $\quad$ Prepared clusters for Kirıkkale city.

\subsection{Center cluster}

The center cluster called as CBD, mainly located in the central section according to the geographical position. This cluster includes the social, economical, cultural, administrative functions and services. There are six neighbourhoods in this cluster which are named Ovacık, Yenidoğan, Hüseyin Kahya, Tepebaşı, Gürler and Kurtuluş.

Cluster 1: This cluster consists of four neighbourhoods which are named Yenimahalle, Yaylacık, Fabrikalar and Kizılırmak, located in the southwest section. This cluster was one of the first areas to be developed. The residential areas of the military industries named as MCIC, are main function of this cluster. Cluster 2: There are four neighbourhoods in this cluster which are named Bağlarbaşı, Kaletepe, Çalılı̈̈z and Güzeltepe, located in the northwest section adjoining the woodland. The main function of it is residential areas.

Cluster 3: This cluster includes two neighbourhoods which are named Sanayi and Etiler, located in the north section. The little industries based automative and residential areas are main users of this cluster.

Cluster 4: There are two neighbourhoods in this cluster which limited Gündoğdu and the west part of Osmangazi, located in the northeast section. It is considered that this cluster has rapid development potentials near future by housing estate. 
Table 1: $\quad$ Characteristics analysis of the clusters.

\begin{tabular}{|c|c|c|c|c|}
\hline Clusters & Geographical Positions & $\begin{array}{c}\text { Areas } \\
\text { (Hectares) }\end{array}$ & $\begin{array}{l}\text { Populations } \\
\text { (Persons) }\end{array}$ & Functions \\
\hline Center & In the center of the city & 160 & 32.000 & Central Business District \\
\hline 1 & In the southwest of the city & 490 & 36.000 & Housing Areas \\
\hline 2 & $\begin{array}{l}\text { In the northwest of the city } \\
\text { and edge of the Woodland }\end{array}$ & 488 & 50.000 & Housing Areas \\
\hline 3 & $\begin{array}{l}\text { In the north of the city } \\
\text { center }\end{array}$ & 570 & 27.000 & $\begin{array}{l}\text { Small Industries and } \\
\text { Housing }\end{array}$ \\
\hline 4 & In the northeast of the city & 533 & 53.000 & Development Housing Area \\
\hline 5 & In the northeast of the city & 383.6 & 40.000 & Development Housing Area \\
\hline 6 & In the east edge of the city & 295.7 & 34.000 & Development Housing Area \\
\hline 7 & In the southeast of the city & 415.9 & 44.000 & $\begin{array}{l}\text { Development Housing and } \\
\text { Agricultural Areas }\end{array}$ \\
\hline 8 & In the southeast of the city & 368.5 & 38.000 & $\begin{array}{l}\text { Development Housing and } \\
\text { Agricultural Areas }\end{array}$ \\
\hline 9 & $\begin{array}{l}\text { In the south of the city } \\
\text { center }\end{array}$ & 345.6 & 24.000 & Housing Areas \\
\hline
\end{tabular}

Cluster 5: This cluster consists of Akşemseddin and the east part of Osmangazi, located in the northeast section. It is considered that this cluster has an upper level of urbanization potentials near future.

Cluster 6: Only one neighbourhood named Kimeski is included in this cluster, which is located in the north of the railway as east section. This cluster like cluster 4 and 5 has rapid development potentials.

Cluster 7: This cluster like cluster 6 , includes only one neighbourhood named Fatih, located in the in the south of the railway as southeast section. The main characteristic of this cluster has agricultural production areas.

Cluster 8: This cluster includes only one neighbourhood named Yuva, located in the southeast section. The main factor influencing this cluster is the problems of environmental pollution. Because the garbage damp of the city is located in this cluster. The main characteristic of this cluster like cluster 7 also has agricultural production areas.

Cluster 9: There are three neighbourhoods in this cluster which are named Bahçelievler, Selim Özer and Karşıyaka, located in the south section adjoining the Military Industrial Areas called MCIC. 


\section{Conclusions: some guidelines to the future}

In this paper, it is suggested a sustainable urban model for Kirıkkale city by the spatial and functional analysis which is defined as cluster analysis. This model includes mainly planning decisions which focused on the sustainable urban development. They are listed below:

-to sustain and assess the ecological potentials such as woodland and agricultural areas, in the urban development process and also decrease or minimize negative effects of industrial areas on ecological sources.

-to reorganize the urban density zones and control urban sprawl.

-to be transformed from monocentric development model to polycentric urban development by planning sub-units as the sub-center which includes social, cultural and economical facilities for increasing of the living environment standards (Figure 4).

-to plan urban open-green systems as the dominant element in urban land use system.

With these decisions, it is considered that the sustainable urban model which has prepared for Kirıkkale is focused on the planned sub-units and founded opengreen system in the context of green city as one of the sustainable urban models (Figure 5).

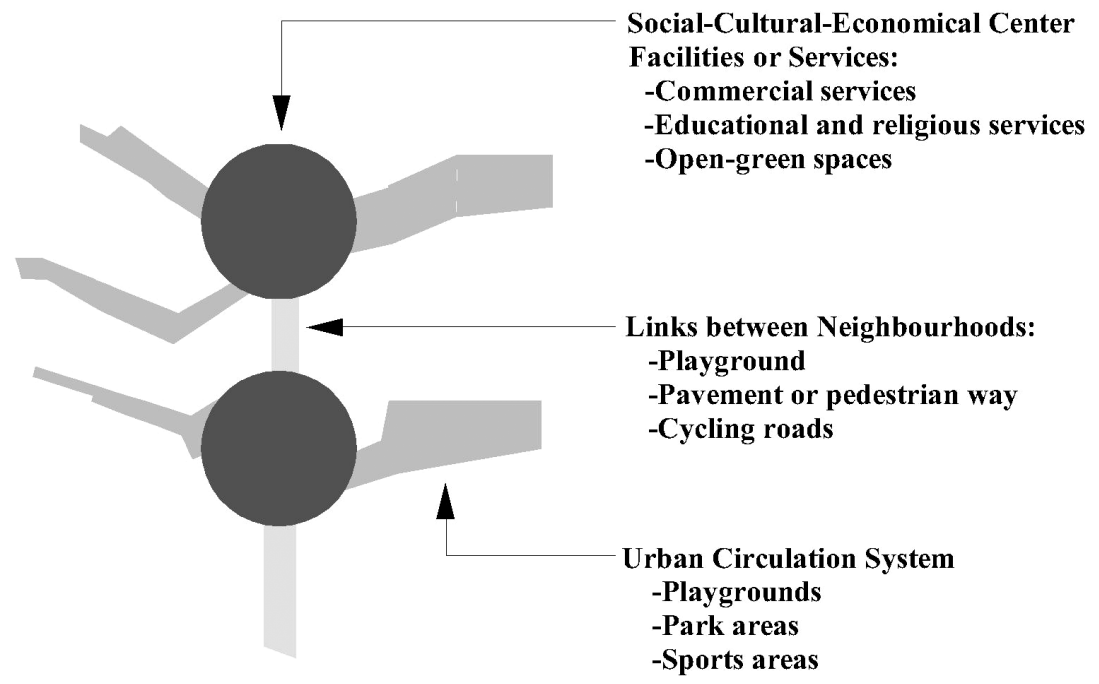

Figure 4: $\quad$ Sub-unit center planned for sustainable development in Kırıkkale city. 


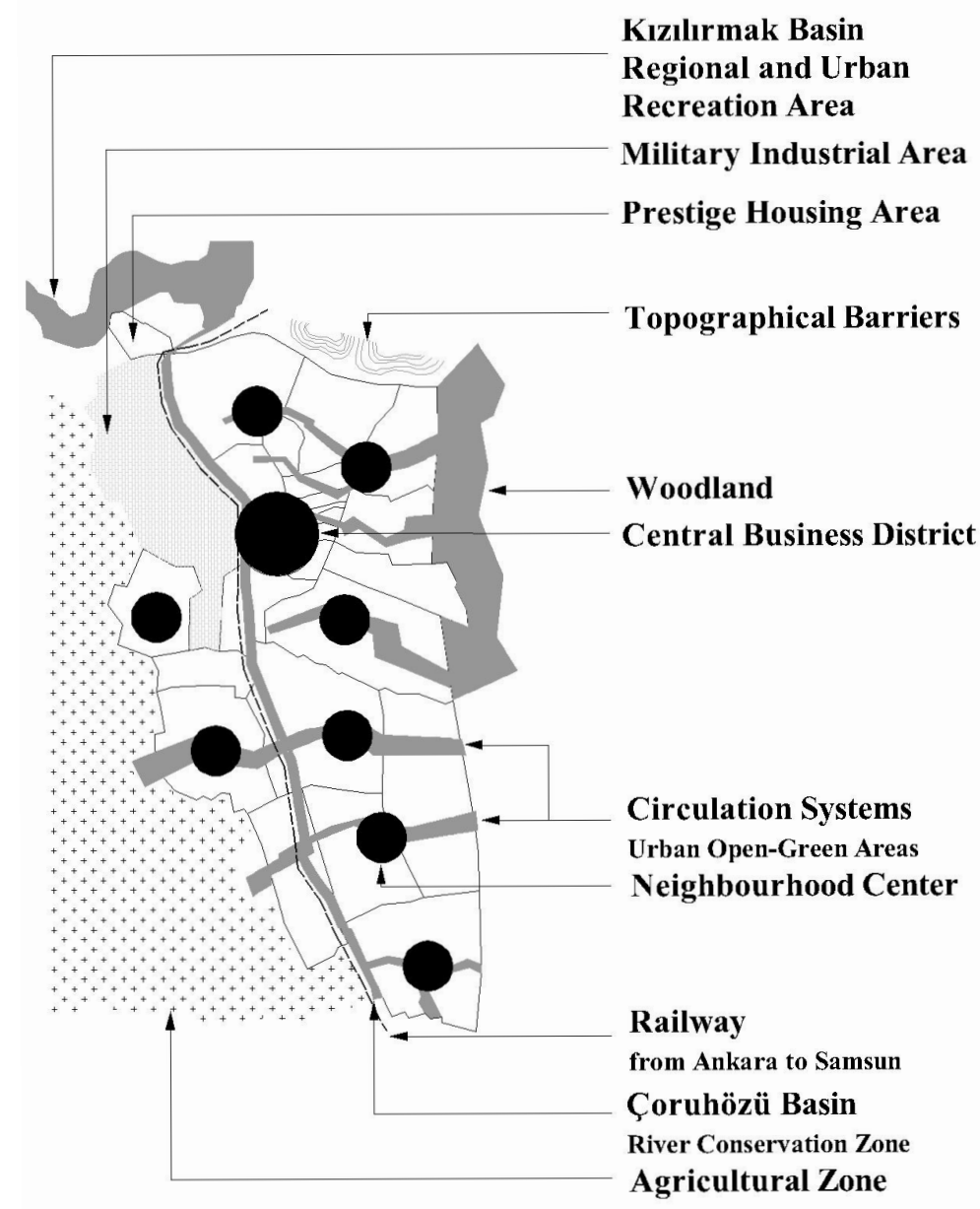

Figure 5: $\quad$ Sustainable urban model for Kirıkale city.

\section{References}

[1] World Commission on Environmental and Development, Our Common Future: The Brundtland Report, Oxford University Press, London, 1987.

[2] Audirac, Ivonne - Fitzgerald, Jennifer, "Information Technology (IT) and Urban Form: An Annotated Bibliography of the Urban Deconcentration and Economic Restructuring Literatures", Journal of Planning Literature, V. 17, S.4, s.480-511, 2003.

[3] Breheny, M. J., "Sustainable Development and Urban Form: An Introduction", Sustainable Development and Urban Form, editor: M. J. Breheny, Pion Limited Press, London, s.1-23, 1992.

[4] Frey, Hildebrand, Designing the City: towards a more Sustainable Urban Form, E and FN Spon Press, New York, 1999. 
[5] Haughton, Graham, "Developing Sustainable Urban Development Models", Cities, V.14, N.4, s.189-195, 1997.

[6] Haughton, Graham-Hunter, Colin, Sustainable Cities, Jessica Kingsley Press, London, 1994.

[7] Naes, Peter, "Urban Planning and Sustainable Development", European Planning Studies, V.9, S.1, s.503-524, 2001.

[8] Talvitie, Juha, The Impact of Information and Communication Technology on Urban and Regional Planning, Helsinki University of Technology Press, Helsinki, 2003. 